\title{
Underwater endoscopic submucosal dissection of a non-granular laterally spreading tumor of the hepatic flexure
}

A 68-year-old man was referred to our hospital for endoscopic treatment of a nongranular pseudodepressed laterally spreading tumor (LST) of the hepatic flexure with a histological diagnosis of adenocarcinoma discovered in another center and for which he refused surgery. At the endoscopic examination, using blue light imaging and linked color imaging (Fujifilm, Valhalla, New York, USA), we observed a nongranular LST with features suggestive of deep submucosal invasion (central depression and Vi pattern according to Kudo classification) (> Fig. 1). An underwater endoscopic submucosal dissection was performed ( $\downarrow$ Video 1 ).

The procedure was carried out using a T-type HybridKnife (Erbe, Tübingen, Germany). To start, an incision was made on the anal side; then the colon was filled with saline, and an underwater submucosal pocket was created under the lesion ( Fig.2). Finally, the circumferential incision was complete and the tumor was removed en bloc. In the end, the muscular layer was clear, without any defects or exposed vessels ( $>$ Fig. $\mathbf{3}$ ). The procedure was completed without any adverse events and the patient was discharged the day after.

The resected specimen ( $\mathbf{F i g . 4}$ ) showed an adenocarcinoma arising in a tubulovillous adenoma, $35 \times 30 \mathrm{~mm}$ in size, with poorly differentiated clusters, infiltration of the submucosa layer (2200 microns), clear margins, aspects of lymphovascular invasion, and low-grade budding. To check for high-risk features of metastatic disease, an abdominal computed tomography was performed and did not show any metastasis. The patient was resent to surgery, which he again refused.

Our case shows that underwater submucosal dissection is safe and effective for complete resection of colic neoplasia [1, 2] even when the submucosal layer is involved.

Endoscopy_UCTN_Code_TTT_1AQ_2AD

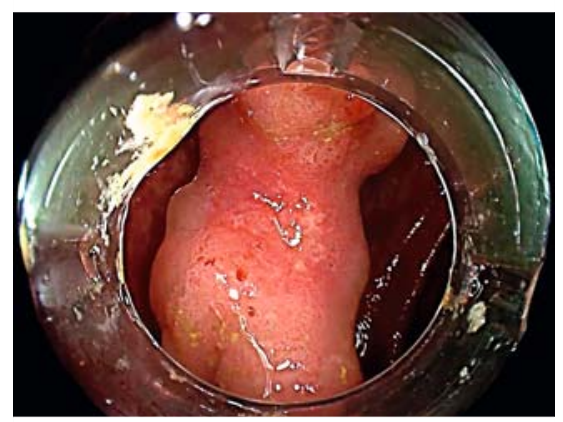

Fig. 1 Nongranular laterally spreading tumor of the hepatic flexure.

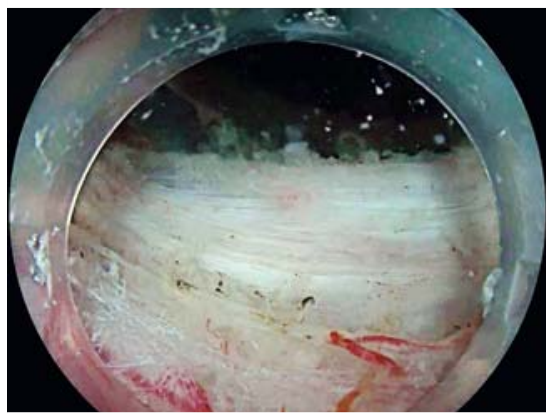

Fig. 3 Result of the resection.

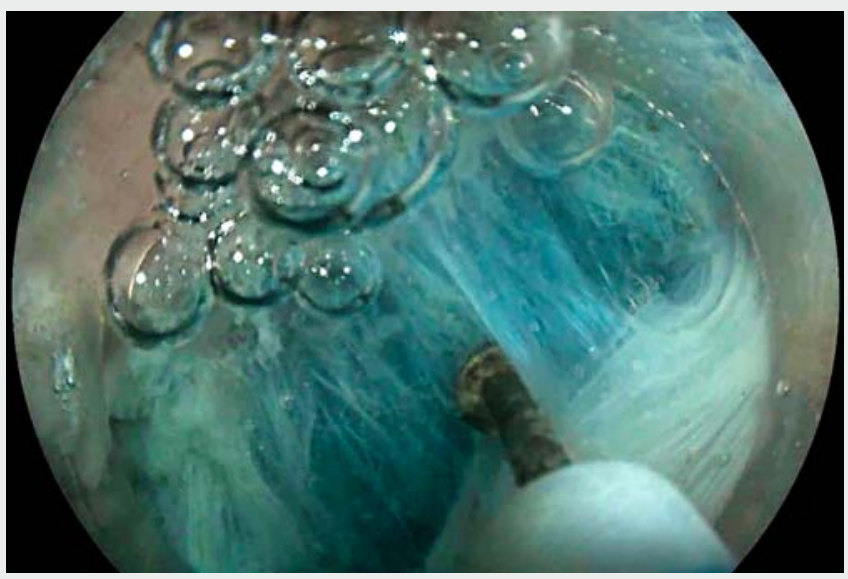

Fig. 4 Resected specimen of the nongranular laterally spreading tumor. $\checkmark$ Video 1 Underwater endoscopic submucosal dissection of a nongranular laterally spreading tumor of the hepatic flexure. 
The authors declare that they have no conflict of interest.

The authors

Paolo Cecinato, Fabio Bassi, Giuliana Sereni, Mariachiara Campanale, Veronica lori, Romano Sassatelli

Unit of Gastroenterology and Digestive Endoscopy, Azienda USL-IRCCS di Reggio Emilia, Italy
Paolo Cecinato, MD

Unit of Gastroenterology and Digestive

Endoscopy, Azienda USL-IRCCS di Reggio

Emilia, 42123 Reggio Emilia, Italy

Fax: +39-0522-295941

paolo.cecinato@ausl.re.it

\section{References}

[1] Nagata M. Usefulness of underwater endoscopic submucosal dissection in saline solution with a monopolar knife for colorectal tumors (with videos). Gastrointest Endosc 2018; 87: 1345-1353

[2] Yoshii S, Akasaka T, Hayashi Y et al. "Underwater" endoscopic submucosal dissection: a novel method for resection in saline with a bipolar needle knife for colorectal epithelial neoplasia. Surg Endosc 2018; 32: 50315036
Bibliography

Endoscopy 2020; 52: E426-E427

DOI 10.1055/a-1158-8620

ISSN 0013-726X

published online 6.5 .2020

(c) 2020. Thieme. All rights reserved.

Georg Thieme Verlag KG, Rüdigerstraße 14 ,

70469 Stuttgart, Germany

\section{ENDOSCOPY E-VIDEOS}

https://eref.thieme.de/e-videos

口回 Endoscopy E-Videos is a free Fection, reporting 靣: on interesting cases and new techniques in gastroenterological endoscopy. All papers include a high quality video and all contributions are freely accessible online.

This section has its own submission website at

https://mc.manuscriptcentral.com/e-videos 